\title{
A Study on the Detectability of Earnings Management via a Normal Accrual Prediction Model
}

\author{
Ryota TAKAhashi ${ }^{1}$ and Ling Feng ${ }^{2}$ \\ ${ }^{1}$ Graduate school of Science and Technology, Tokyo University of Science, Noda-shi, Chiba-ken, 278-8510, Japan \\ ${ }^{2}$ Faculty of Science and Technology, Tokyo University of Science, Noda-shi, Chiba-ken, 278-8510, Japan
}

\begin{abstract}
Earnings management research started in the 1970s has been developed. In the empirical research, the research area on the method of detecting earnings management is the basis of all earnings management research. In recent years, however, many criticisms have been made on the normal accrual prediction model, which is the most commonly used method of detecting earnings management in this field of study. From this view point, this paper intends to consider the detectability of earnings management with abnormal accruals calculated using normal accrual prediction model.
\end{abstract}

Key Words : earnings management, normal accrual prediction model, method of detecting earnings management

\section{Introduction}

Initial research on earnings management began in the 1970s under the assumption that manager aims to maximize its own gain. Earnings management research split into three areas: (1) earnings management methods and detection; (2) earnings management motives and goals; and (3) the economic consequences of earnings management, and has developed along those lines to the present.

Research on (1) earnings management methods and detection is an area of research that splits earnings management behavior into accounting discretionary behavior and substantive discretionary behavior and attempts to detect the presence or absence of discretionary behavior [5],[8]. Research on (2) earnings management motives and goals is a research area that explores contract theory that managers adjust profits so that they benefit themselves when fulfilling contracts with stakeholders [9],[11], as well as a stock market theory that management will adjust profits to manipulate stock prices with some intention [7],[9]. Research on (3) economic consequences by earnings management is an area of research that captures the relationship between the presence or absence of earnings management and accompanying changes in corporate value or stock price [10],[12].

In recent years, earnings management studies developed from (1) to (3) have been criticized as "unscientific" [1],[13]. The basis for this is doubt regarding the validity of the research field in relation to (1) earnings management methods and detection. Research areas (2) and (3) rely on the earnings management detection methods in (1) for analysis. As such, the research related to (1) earnings management methods and detection is the foundation for the other research areas, and as long as the validity of that research is not assured, all of the

Corresponding Author: Ryota Takahashi

Graduate school of Science and Technology, Tokyo University of Science, 2641 Yamazaki, Noda-shi, Chiba-ken, 278-8510, Japan

fengl@rs.noda.tus.ac.jp

(Received July 26, 2019)

(Revised September 25, 2019)

(Accepted October 20, 2019) research fields will be called into question. This paper will focus on the earnings management detection methods criticized in recent years while considering the background of the field of earnings management research.

The subject of the criticisms has centered on and around the normal accrual prediction model. Abnormal accruals are generally used as proxy variables for discretionary accounting behavior, but these abnormal accruals are not directly visible on financial statements. This leads to assuming normal accruals which occur through normal business activity, and thinking that abnormal accruals occur outside normal economic activity (i.e., earnings management), which are deducted from accruals calculated from financial statements. The regression model that predicts these normal accruals is the normal accrual prediction model.

This paper considers the normal accrual prediction model, which is the detection method for earnings management (accounting discretionary behavior), and aims to examine the model's detection capabilities. The specific issues with a detection method that handles examinations and the results that follow them are:

A) Accrual calculation methods and interpretation issues as well as the resulting earnings management over-(under-) detection and false distinctions

B) Estimation method issues and the resulting earnings management over-(under-) detection and false distinctions

C) Abnormal accrual interpretation issues the resulting earnings management direction misdetection

Intending to investigate the detection capability for earnings management behavior in each of these three categories by examining calculated abnormal accruals, in this paper, we analyze the issues of accrual and normal accrual prediction models, demonstrate the detection of earnings management by normal accrual prediction models, and show a solution to the underformulation issue of normal accrual prediction models. 


\section{Earnings management research}

This section will split prior research on earnings management into three areas and summarize the same: (1) earnings management methods and detection, (2) earnings management motives and goals, and (3) the economic consequences of earnings management. Then, it will confirm the issues with earnings management detection methods within the implicated field of (1).

\subsection{Earnings management research}

\subsubsection{Earnings management methods and detection}

The methods for detecting earnings management are divided into four categories.

\section{i Investigate profit distribution}

\section{ii Investigate comprehensive indicators}

iii Investigate easily manipulated profit and loss items

iv Investigate the accounting methods of each company

The profit distribution investigation method is visually appealing and examines whether the histogram distribution of accounting profits for profit benchmarks (zero profit, previous period's profit, management forecasts, etc.) is discontinuous before and after profit benchmarks.

Profit is broken down into cash flow (hereinafter, CF) and accruals, and there is a method for investigating accruals wherein earnings management appears in the accruals that require a manager's estimates and discretion [5]. Additionally, as there are areas (normal accruals) that necessarily appear due to management activity even within accruals, there is also a method for investigating abnormal accruals by subtracting normal accruals from accruals. These methods comprehensively investigate corporate earnings managements, which leads to investigating a second comprehensive indicator. This method does not indicate what sort of method is being used to adjust profits. The third method is to investigate the profit and loss items influenced by the entries used to generate accruals and changes in management activity.

Finally, there is the method for detecting the presence of earnings management by individually verifying each note on the securities report for each corporation. This method cannot observe analysis or trends for a business group, so its sociological usefulness is low. As such, methods II and III, which are capable of comparative analysis within a business group, are currently the primary methods for detecting earnings management.

\subsubsection{Earnings management motivation and goals}

The motivations and goals of earnings management are broadly divided into contract theory and stock market theory. Contract theory is supported by a large body of research, and covers debt contract theory, compensation agreement theory, and tax cost theory, where stock market theory has profit benchmark theory, stock compensation theory, and M\&A theory.

Debt contract theory is said to be a profit-inflating type of earnings management for companies with a high probability of interfering with fund procurement in the event of a conflict with a financial reserve clause in a debt contract [11]. Compensation agreement theory is a type of profit-inflating adjustment undertaken by a company's managers when said company has a bonus system tied to profits, and that company's profits exceed the target profit amount set by the system while not reaching the upper limit of the bonus amount. Shuto [9] observes a positive relationship when analyzing the explained variable as the total of executive compensation and executive bonuses, and the explanatory variable as normal accruals. Tax cost theory is the theory that companies adjust profits by inflation (minimization) in order to pay the minimal amount of corporation tax.

Profit benchmark theory is in the vicinity of profit benchmarks like zero profits, previous period's profits, and management predictions, and covers the idea that companies that fall below these benchmarks adjust profits upward [9]. Stock compensation theory is the theory that companies with stock options or company stock adjust profits by inflating the same. Additionally, M\&A theory is the theory that companies purchasing other companies will inflate profits to make the terms of the purchase favorable in terms of the exchange ratio and the like. Natsume [7] analyzed the relationship between M\&A and substantive discretionary behavior, pointing out the trend that acquiring companies exchanging stocks will reduce discretionary costs.

\subsubsection{Economic consequences of earnings management}

Accruals, which are the proxy variable for earnings management, and abnormal accruals were long ago confirmed as containing informative content in the stock market. However, there is debate about this result and whether earnings management ultimately misleads investors' decisions or whether they are releasing internal intelligence. Subramanyam [10] finds that the market prices for abnormal accruals, meaning that the market sees through a company's profit adjusting and formulates the stock price accordingly. On the other hand, Xie [12] suggests, upon investigating the market response to the sustainability of discretionary items, that the sustainability of abnormal accruals is overvalued, meaning that the market is led by companies' earnings managements.

\subsection{Criticisms of earnings management detection methods}

The earnings management research that began in the 1970s has, thus far, accomplished the development and economic consequences, motivation, and goals of earnings management. However, upon entering the 2010 s, the earnings management detection methods that form the foundation of the research began to be increasingly called into question [1],[13]. These criticisms are mainly focused on the Jones Model, the most frequently used model, and its modified version. The Jones model is criticized as having issues with underestimation, as well as with interpretations of accrual definitions, abnormal accrual interpretations, and sample selection.

The modified model, in addition to these issues, is also criticized for its estimation methods and application outside of event studies. The criticisms of the detection methods for earnings management are especially strong, and the doubts about its validity could be connected to the significance of earnings management research itself. This paper investigates the issues with the normal accrual prediction model and detectability of earnings managements. 


\section{Normal accrual prediction model}

This section summarizes the normal accrual prediction model as a detection method for earnings management and its theoretical background.

\subsection{Various prediction model theories}

Jones Model [6]

$$
\text { Tacc }=\alpha_{0}+\alpha_{1} \Delta \text { Sale }+\alpha_{2} P P E+\epsilon
$$

Modified Jones Model [3]

$$
\text { Tacc }=\alpha_{0}+\alpha_{1}(\Delta S \text { ale }-\triangle A R)+\alpha_{2} P P E+\epsilon
$$

Forward-Looking Model [4]

$$
\begin{array}{r}
\text { Tacc }=\alpha_{0}^{\prime}+\alpha_{1}^{\prime}((1+\kappa) \Delta S \text { ale }-\Delta A R)+\alpha_{2}^{\prime} P P E \\
+\alpha_{3}^{\prime} L_{a g} \text { Tacc }+\alpha_{4}^{\prime} G R \_S \text { ale }+\epsilon
\end{array}
$$

Tacc : Accruals

$\triangle$ Sale : Changes in sales

$P P E \quad$ : Depreciable property and equipment

$\triangle A R \quad$ : Increase in accounts receivable

$G R \_$Sale : Sales growth rate

Lag_Tacc. Previous period accrual

$\kappa \quad$ : Regression coefficient $\kappa$ from

$$
\Delta A R=\alpha+\kappa \Delta \text { S ale }
$$

The Jones Model was proposed by Jones [6] as a normal accrual prediction model, and is the basis of the Modified Jones Model and Forward-Looking Model. The Jones Model attempts to explain normal accruals via sales increases and depreciable property and equipment. Accruals have a proportional relationship to sales increases, and since depreciation expenses are included in the calculation of accruals, these two form the model's explanatory variables.

The Modified Jones Model is an accrual model proposed by Dechow et al.[3]. The value of sales increases is captured by changes in accounts receivable, and these changes in accounts receivable could be distorted through management discretion. As such, changes in sales are extracted from changes in accounts receivables. The Modified Jones Model performs its coefficient estimates using the Jones Model, then uses those coefficients in formula (2) to predict normal accruals.

The Forward-Looking Model is an accrual model proposed by Dechow et al.[4]. The first characteristic of the ForwardLooking Model is that it considers all $\triangle A R$ as discretionary, as in the Modified Jones Model and, rather than $(\triangle S$ ale $-\triangle A R)$, the portion that normally occurs returns in line with $\Delta S$ ale within $\triangle A R$. The second characteristic is that it adds the previous period's $T a c c$ as an explanatory variable. While accruals flip in the long-term, this is thought to have a degree of persistence, so it was added to capture that influence.

The third is the basis for the Forward-Looking Model's name. Changes in the current period's inventory assets are a factor in the change in accruals. Changes in inventory do not necessitate earnings management through overproduction due to management discretion. This is because, if management is anticipating high growth in the next period, there is a chance they will increase the inventory balance for the current period. Should sales be increasing from the current period into the next period, management will anticipate this and increase inventory balances, and while taking place in the past, due to the above reasons, the model judges that this is likely, so includes increases in sales as an explanatory variable.

\subsection{Proof of linearity in the normal accrual prediction model}

This section uses a simplified model of Dechow and Watts [2] to explain the basis for including changes in sales in the normal accrual prediction model. The variables used in the model are: Sale for sales, $\pi$ for return on sales, $\gamma$ for sales ratio (proportion of accounts receivable within sales), $A R$ for accounts receivable, Tacc for accruals, $C F$ for business cash flow, and $\Pi$ for profit. Additionally, the following four assumptions are made:

i Sales follow a random walk: $\left(\right.$ Sale $_{t}=$ Sale $\left._{t-1}+\epsilon_{t}\right)$

ii $\pi$ and $\gamma$ are constants

iii End of period $A R$ are fully recovered in the next period

iv Products are acquired entirely with cash and inventories are not retained

Under those assumptions, it is possible to acquire the current period's $C F$ as follows:

$$
C F_{t}=(1-\gamma) \text { Sale }_{t}-(1-\pi) \text { Sale }_{t}+A R_{t-1}
$$

Here, substitute $A R_{t-1}=\gamma S$ ale $_{t-1}$, and from sales following a random walk $\left(\right.$ Sale $_{t}=$ Sale $\left._{t-1}+\epsilon_{t}\right)$ :

$$
\begin{aligned}
C F_{t} & =(1-\gamma) \text { Sale }_{t}-(1-\pi) \text { Sale }_{t}+\gamma \text { Sale }_{t-1} \\
& =\pi \text { Sale }_{t}-\gamma\left(\text { Sale }_{t}-\text { Sale }_{t-1}\right) \\
& =\pi \text { Sale }_{t}-\gamma \epsilon_{t}
\end{aligned}
$$

This means current period profits are $\Pi=\pi$ Sale $=C F+$ Tacc. Thus:

$$
\begin{aligned}
\text { Tacc }_{t} & =\pi \text { Sale }_{t}-C F \\
& =\pi \text { ale }_{t}-\left(\pi S \text { ale }_{t}-\gamma \epsilon_{t}\right) \\
& =\gamma \epsilon_{t}
\end{aligned}
$$

$\epsilon_{t}=$ Sale $_{t}-$ Sale $_{t-1}=\Delta$ Sale $_{t}$ shows that accruals are proportional to and come from changes in sales. This shows that accruals and changes in sales have a linear relationship.

\section{Issues and their countermeasures in the normal ac- crual prediction model}

This section classifies the issues that appear when predicting normal accruals and the results caused by this below, and each section explains this paper's approach to each:

A) Accrual calculation methods and interpretation issues as well as the resulting earnings management over-(under-) detection and false distinctions

B) Estimation method issues and the resulting earnings management over-(under-) detection and misidentifications

C) Abnormal accrual interpretation issues the resulting earnings management direction misdetection 


\subsection{Accrual calculation methods and interpretation issues as well as the resulting earnings management over- (under-) detection and false distinctions}

As shown in table 1, methods for calculating accruals differ by researcher according to the desired value. Variable estimation is done with accruals as the response variable, so if the calculated accrual is excessive or missing an element, it is possible that the calculated abnormal accruals will ultimately lead to over(under-) detection or make a false distinction about earnings management. In line with this, it is necessary to verify the components of each accrual and investigate whether the influence of the excessive (insufficient) elements is minor. In light of the above, this paper uses the following five major accrual calculation methods seen in earnings management research, calculates abnormal accruals, and examines the same.

Earnings management is divided into two categories: adjustment due to changes in accounting policy that do not directly influence $\mathrm{CF}$ - adjustments due to changes in practical management activity during the period like accounting discretionary behavior and sales manipulation or a reduction in discretionary costs - and substantive discretionary behavior. A great deal of research uses abnormal accruals as a proxy variable for accounting discretionary behavior and the value from investigating individual profit and loss items as the proxy variable for substantive discretionary behavior. Roychowdury [8] divides substantive discretionary behavior into three categories: excessive production, reducing discretionary costs, and manipulation of credit transactions, then uses each as proxy variables for abnormal manufacturing costs, abnormal discretionary costs, and abnormal business $\mathrm{CF}$, respectively.

In recent years, much analysis has been done with these three as representative proxy variables for substantive discretionary behavior, and research analyzing the relationship between accounting and substantive discretionary behavior is increasing. However, as classifications for earnings management methods, both accounting and substantive discretionary behavior are on equal footing, but as proxy variables their relationship is not equal for abnormal accruals as well as excessive production, reducing discretionary costs, and manipulation of credit transactions. They have a hierarchical relationship, and the influence of excessive production and manipulation of credit transactions are included in abnormal accruals. As such, it is not appropriate to use abnormal accruals as a proxy variable for accounting discretionary behavior "only," and abnormal business CF, abnormal manufacturing costs, and abnormal accruals should not be considered in the same analysis.

\subsection{Estimation method issues and the resulting earnings management over- (under-) detection and misidentifi- cations}

The estimation methods used by researchers also vary. Jones [6] uses a time series estimation as well as different coefficient estimation periods and prediction periods. However, crosssection estimation and panel estimation are frequently adopted in terms of securing sample size, and plenty of research has been conducted in which the coefficient estimation period and event periods are the same (Figure 1).

Jones [6] requires 14 years of data for one company when performing a time series estimation. However, there is an issue with constancy, and considering recent industrial development and the speed of change in industry types, it is difficult to believe the business structure will remain the same for 14 years. Furthermore, if there is any correlation between earnings management and the business' survival, the internal validity will be compromised.

In cross-section estimation, there must be a common attribute within the group outside of earnings management. This theory is also unrealistic. However, within the same industry, it is true that the similarity of factors (depreciation methods, transaction structures, etc.) that influence accruals is recognized.

Panel data estimation is a compromise between time series and cross-section estimation, so it has one or both of the issues of constancy and commonality. However, even if panel data estimation cannot be done over multiple years, it is possible to secure a sample size that can relieve the constancy issue. Company differences in the cross-section can be resolved by using a linear mixed model. A linear mixed model can consider both industry trends (global effects) and company trends (local effects), which can resolve the issues in cross-section, and further, this is considered to enable better predictions. Following this, this paper uses panel data and attempts normal accrual prediction via a linear mixed regression.

Much earnings management research uses either crosssection estimation or panel data estimation. However, with regard to factors that influence accruals, companies that deviate significantly from the industry average within these estimations get an overestimated earnings management. Additionally, for companies with large internal changes that hide them when looking at them from the industry average, this will misidentify or under-determine their earnings management. Thus, linear mixed models, which can consider company differences while also taking the entire industry into consideration are thought to have some value in detecting earnings management.

As for whether having the coefficient period and prediction period differ or be the same, this is closely tied to the interpretation of abnormal accruals, and will be discussed in the next section.

\subsection{Abnormal accrual interpretation issues the resulting earnings management direction misdetection}

Accruals not distorted by managers (normal accruals) cannot be known by external people. In other words, the normal accrual prediction model attempts to use accruals distorted by managers to predict normal accruals using a regression equation. This is quite contradictory, and it is not realistic to make calculated abnormal accruals the proxy variable for earnings managements by managers. So long as calculations are done by regression, interpreting abnormal accruals to be whether or not increasing-type (decreasing-type) earnings managements are being done more during the prediction period than earnings managements with the average of the coefficient estimation period could be considered reasonable.

For example, should the earnings management amount of a profit-increase type during the prediction period be smaller than the average profit-increase type's earnings management amount during the coefficient estimation period, abnormal accruals would end up with a negative value. Based on the interpretation of the former, this could conclude that profitreducing type earnings management took place. Consequently, this would lead to misidentifying the direction of earnings man- 
Table 1 Accrual calculation formulas

Calculated from profit and loss statements and balance sheets

Accrual 1 ( $\Delta$ Current Assets $-\Delta$ Cash Equivalents $)-(\Delta$ Current Liabilities $-\Delta$ Short-term Debts $)-(\Delta$ Long - term Reserves + Depreciation $)$

Calculate from (Operating Cash Flow)-(Profit)

Accrual 2 (Operating CF)-(Net Income Before Tax)

Accrual 3 (Operating CF)-(Net Income After Tax)

Accrual 4 (Operating CF)-(After Tax Ordinary Income), where (After Tax Ordinary Income)=(After Tax Net Income) $-($ Extraordinary Losses)

Calculated from cash flow statement items

Accrual5 $\Delta$ Accounts Receivable $+\Delta$ Inventory $+\Delta$ Other Current Assets $-\Delta$ Accounts Payable $-\Delta$ Other Current Liabilities $-\Delta$ Short - term Credit -Depreciation Expenses

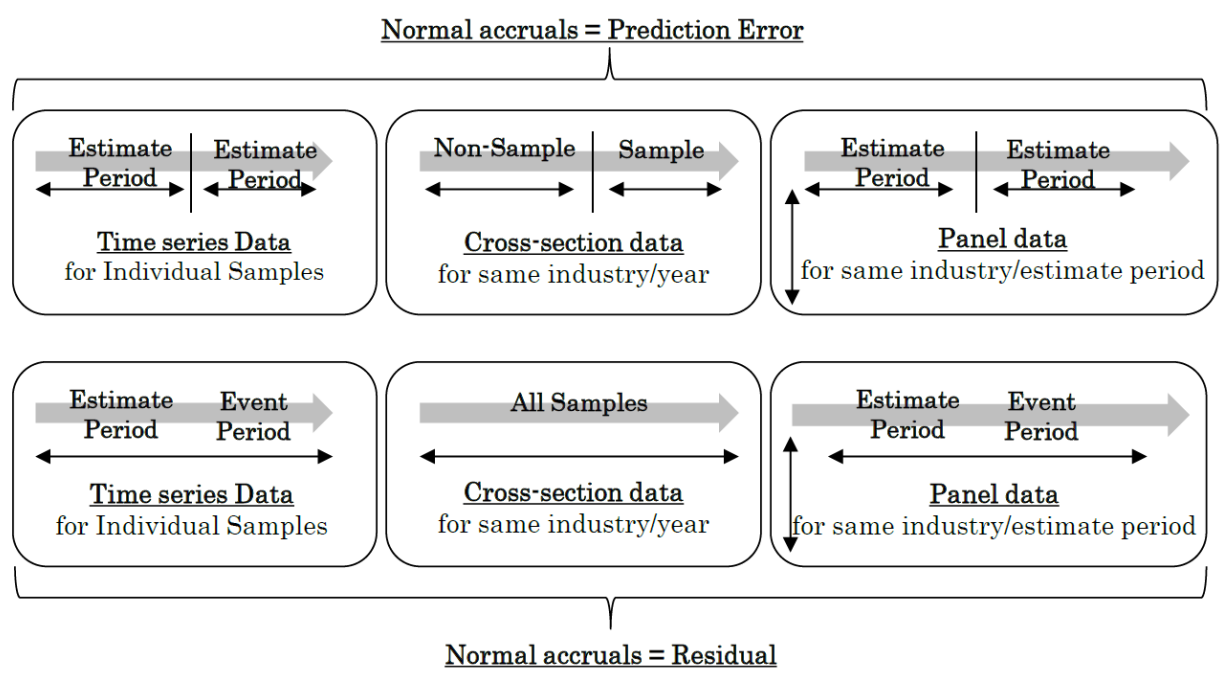

Fig. 1 Estimation method, coefficient estimate and prediction period

agement due to the interpretation method for the abnormal accrual. Being unable to observe the sign of the abnormal accrual attention is due to the fact that the amount of abnormal accrual is not the amount of earnings management. In other words, analysis that includes abnormal accruals in the analysis' explanatory variable as a rank for earnings management amount could be considered meaningless.

Regarding the coefficient estimation period and prediction period, a different period could be considered better beyond the interpretation of abnormal accrual being 'whether or not increasing-type (decreasing-type) earnings managements are being done more during the prediction period than earnings managements with the average of the coefficient estimation period.'

\section{Research design: normal accrual prediction meth- ods}

This section calculates abnormal accruals using various accrual calculation methods and a normal accrual prediction model, then examines where earnings management behavior (above the average for the coefficient estimate sample) is actually detectable in each company using a linear regression model and a linear mixed regression model.

\subsection{Samples}

The samples are selected based on the following criteria:

i Listed on the Tokyo Stock Exchange 1st section

ii Manufacturing industry (excludes ship building / cars / transport equipment) iii Reported financials on March 31st

iv Estimate sample: reported financials between March, 2012 and March, 2016

v Event sample: reported financials in March, 2017

Financial Data was obtained from "Nikkei NEEDS Financial QUEST." The sample count, with companies having missing values removed, is in Table 2 .

Table 2 Sample numbers for this paper

\begin{tabular}{|l|c|c|}
\hline Industry & $\begin{array}{c}\text { Prediction Samples } \\
\text { Number }\end{array}$ & $\begin{array}{c}\text { Coefficient Estimate } \\
\text { Samples Number }\end{array}$ \\
\hline Rubber & 6 & 30 \\
\hline Products Food & 44 & 220 \\
\hline Precision Machines & 20 & 100 \\
\hline Oil & 5 & 25 \\
\hline Textiles & 23 & 115 \\
\hline Steel & 27 & 135 \\
\hline Electrical Equipment & 100 & 500 \\
\hline Nonferrous & 43 & 258 \\
Products & 24 & 120 \\
\hline Ceramics & 35 & 175 \\
\hline Other Manufacturing & 10 & 50 \\
\hline Pulp / Paper & 19 & 95 \\
\hline Medicine & 83 & 415 \\
\hline Chemistry & 94 & 470 \\
\hline Machines & & \\
\hline
\end{tabular}

\subsection{Linear mixed model summary}

When performing normal accrual predictions using panel data estimation, the data used were in a nest structure as in Figure 2. 
When in this type of structure, it is possible for each variable to generate interclass correlation. This is one of the reasons to use a linear mixed model.

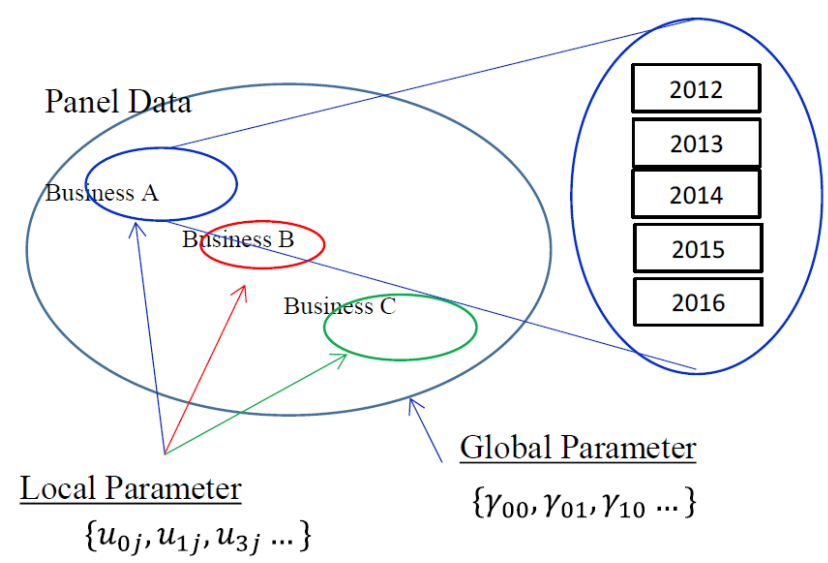

Fig. 2 Relationship between data structure

This paper makes coefficients that differ by company (company differences) into local parameters, and coefficients that are the same across the industry into global parameters. The company differences primarily considered in this paper are the amount of change in sales $\left(\triangle S\right.$ ale $\left._{t, i}\right)$ and depreciable property and equipment $\left(P P E_{t, i}\right)$. In addition, $t$ and $i$ define index displaying year and company. Changes in sales can be thought of as proportional to accruals when the accounts receivable ratio is made into a coefficient. It is possible to assume that there are terms of credit and an accounts receivable ratio, so they are considered local effects. Depreciable property and equipment are considered a local parameter, since it has a high interclass correlation of about 0.88 and years of depreciation and method can be thought of as bias by managers.

Additionally, it is likely that calculated accruals have inertia. Essentially, it is highly likely that the previous and current period's accruals are auto-correlated. This means indicating a first-order auto-correlation structure for internal error $e_{i, t}$, then estimating accruals.

\subsection{Normal accrual prediction model applied in this paper}

This paper estimates coefficients using formula (7), formula (9), formula (10), and formula (15), then predicts normal accruals using formula (7) - formula (9) and formula (10) - formula (20). Coefficients of formula (8) and formula (11) are estimated with formula (7) and formula (10). Formulas (10) - formula (20) are model formulas that use a linear mixed model. Accruals are estimated using five calculation methods, and abnormal accruals are calculated for each of those accruals. Additionally, regressions are performed using panel data assembled from industries where the coefficient estimation period and sample period are not the same. All variables have undergone in-group centering.

- Linear Model

$$
\begin{aligned}
\operatorname{Tacc}_{t, i}= & \alpha_{0}+\alpha_{1} \Delta \text { Sale }_{t, i}+\alpha_{2} P P E_{t, i}+\epsilon_{t, i} \\
\operatorname{Tacc}_{t, i}= & \alpha_{0}+\alpha_{1}\left(\Delta \text { Sale }_{t, i}-\Delta A R_{t, i}\right)+\alpha_{2} P P E_{t, i}+\epsilon_{t, i} \\
\operatorname{Tacc}_{t, i}= & \alpha^{\prime}{ }_{0}+\alpha^{\prime}{ }_{1}\left(\left(1+\kappa_{i}\right) \Delta \text { Sale }_{t, i}-\Delta A R_{t, i}\right)+\alpha^{\prime}{ }_{2} P P E_{t, i} \\
& +\alpha^{\prime}{ }_{3} \text { Lag_Tacc }_{t, i}+\alpha^{\prime}{ }_{4} \text { GR_Sale }_{t, i}+\epsilon_{t, i}
\end{aligned}
$$

- Linear Mixed Model

$$
\begin{aligned}
\operatorname{Tacc}_{t, i}= & \alpha_{0, i}+\alpha_{1, i} \Delta \text { Sale }_{t, i}+\alpha_{2, i} P P E_{t, i}+e_{t, i} \\
\operatorname{Tacc}_{t, i}= & \alpha_{0, i}+\alpha_{1, i}\left(\Delta \text { Sale }_{t, i}-\Delta A R_{t, i}\right)+\alpha_{2, i} P P E_{t, i}+e_{t, i} \\
\alpha_{0, i}= & \gamma_{00}+\gamma_{01} \Delta \text { Sale }_{0, i}+\gamma_{02} P P E_{0, i}+u_{0, i} \\
\alpha_{1, i}= & \gamma_{0}+u_{1, i} \\
\alpha_{2, i}= & \gamma_{20}+u_{2, i} \\
\operatorname{Tacc}_{t, i}= & \alpha^{\prime}{ }_{0, i}+\alpha^{\prime}{ }_{1, i}\left(\left(1+\kappa_{i}\right) \Delta \text { Sale }_{t, i}-\Delta A R_{t, i}\right)+\alpha_{2, i}^{\prime} P P E_{t, i} \\
& +\alpha^{\prime}{ }_{3, i} \text { Lag_Tacc }_{t, i}+\alpha^{\prime}{ }_{4, i} G R \_S a l e_{t, i}+e_{t, i} \\
\alpha^{\prime}{ }_{0, i}= & \left.\gamma_{00}+\gamma_{01} \Delta S \text { ale } e_{0, i}+\gamma_{02} P P E_{0, i}\right)+u_{0, i} \\
\alpha_{1, i}^{\prime}= & \gamma_{10} \\
\alpha_{2, i}^{\prime}= & \gamma_{20}+u_{2, i} \\
\alpha_{3, i}^{\prime}= & \gamma_{30} \\
\alpha^{\prime}{ }_{4, i}= & \gamma_{40} \\
\Delta A R_{t, i}= & \beta_{0, i}+\kappa_{i} \Delta \text { Sale }_{t, i} \\
\beta_{0, i}= & \gamma_{10}^{\prime}+u_{0, i}^{\prime} \\
\kappa_{i}= & \gamma_{10}^{\prime}+u_{1, i}^{\prime}
\end{aligned}
$$

$t \quad$ : Index displaying year

$i \quad$ : Index displaying company

Tacc : Accrual 1 - Accrual 5

$\triangle S$ ale : Changes in sales

$P P E \quad$ : Depreciable property and equipment

$\triangle A R \quad$ : Increases in accounts receivable

$G R \_$Sale : Sales growth rate

Lag_Tacc. Previous period accrual

$\kappa \quad:$ Regression coefficient $\kappa$ from $\Delta A R_{t, i}=\beta_{0}+\kappa \Delta$ Sale $_{t, i}$

$\kappa_{i} \quad$ : Mixed regression coefficient $\kappa_{i}$ from formula (21)

\section{Examining detectable earnings managements in the normal accrual prediction model}

This section examines abnormal accruals calculated from various accruals and normal accrual prediction models.

\subsection{Examining accruals}

When the components of each accruals indicated by tabel 1 are decomposed into the account level, it becomes table 3. Figure 3 shows average and median of all samples for each accrual. Every accrual calculation method has items that are either too large or too small. In particular, the calculation method for Accrual 2 sees every item calculated using an indirect method from the CF statement as an accrual. It is possible to do the simplest calculation with only the CF statement, but in actuality there is a high chance that the result will be significantly different from the true accrual value. This is because profits and losses that cannot be included in $\mathrm{CF}$ are introduced to indirectmethod items in the CF statement by finance and investment activities. This is especially true for corporate tax, which is not insignificant and is appropriated every period, pushing accruals in the correct direction. This trend can be seen even in Figure 3 , which compares the representative values for each accrual. It is there that this paper conducts a comparison between groups for each of the accruals.

Since each accrual is corresponds and non-parametric, a Kruskal-Wallis one-way analysis of variance test was performed. The results showed that there were differences in each accrual, so multiple comparisons were made (Figure 4). These 
Table 3 Main components of each accrual

\begin{tabular}{|c|c|c|c|c|c|}
\hline & Accrual 1 & Accrual 2 & Accrual 3 & Accrual 4 & Accrual 5 \\
\hline \multirow{8}{*}{$\begin{array}{l}\text { Component } \\
\text { (Partial) }\end{array}$} & Depreciation Expenses & Depreciation Expenses & Depreciation Expenses & Depreciation Expenses & Depreciation Expenses \\
\hline & $\Delta$ Long-term Reserves & Impairment Loss & Impairment Loss & $\begin{array}{l}\text { Amortization of Good- } \\
\text { will }\end{array}$ & $\Delta$ Accounts Receivable \\
\hline & $\Delta$ Accounts Receivable & $\begin{array}{l}\text { Amortization of Good- } \\
\text { will }\end{array}$ & $\begin{array}{l}\text { Amortization of Good- } \\
\text { will }\end{array}$ & $\Delta$ Long-term Reserves & $\Delta$ Inventory \\
\hline & $\Delta$ Inventory & $\Delta$ Long-term Reserves & $\Delta$ Long-term Reserves & $\Delta$ Accounts Receivable & $\Delta$ Accounts Payable \\
\hline & $\Delta$ Accounts Payable & $\Delta$ Accounts Receivable & $\Delta$ Accounts Receivable & $\Delta$ Inventory & Other Current Assets \\
\hline & $\Delta$ Other Current Assets & $\Delta$ Inventory & $\Delta$ Inventory & $\Delta$ Accounts Payable & $\Delta$ Other Current Liabilities \\
\hline & $\begin{array}{l}\Delta \text { Other Current Liabili- } \\
\text { ties }\end{array}$ & $\Delta$ Accounts Payable & $\Delta$ Accounts Payable & & \\
\hline & etc.. & etc.. & etc.. & etc.. & \\
\hline \multirow{4}{*}{ Excess } & & $\begin{array}{l}\text { Gain on Sale, Evalua- } \\
\text { tion, and Removal of } \\
\text { Fixed Assets }\end{array}$ & $\begin{array}{l}\text { Gain on Sale, Evalua- } \\
\text { tion, and Removal of } \\
\text { Fixed Assets }\end{array}$ & $\begin{array}{l}\text { Special Profit and Loss } \\
\text { Items (Receipt Security } \\
\text { Fees, etc.) }\end{array}$ & \\
\hline & & Damages & Damages & & \\
\hline & & $\begin{array}{l}\text { Business Restructuring } \\
\text { Loss }\end{array}$ & $\begin{array}{l}\text { Business Restructuring } \\
\text { Loss }\end{array}$ & & \\
\hline & & Corporate Tax & & & \\
\hline \multirow{3}{*}{ Deficiency } & Impairment Loss & & & Impairment Loss & Impairment Loss \\
\hline & $\begin{array}{l}\text { Amortization of Good- } \\
\text { will }\end{array}$ & & & & $\begin{array}{l}\text { Amortization of Good- } \\
\text { will }\end{array}$ \\
\hline & & & & & $\begin{array}{l}\Delta \text { Long-term Reserves, } \\
\text { etc.. }\end{array}$ \\
\hline
\end{tabular}

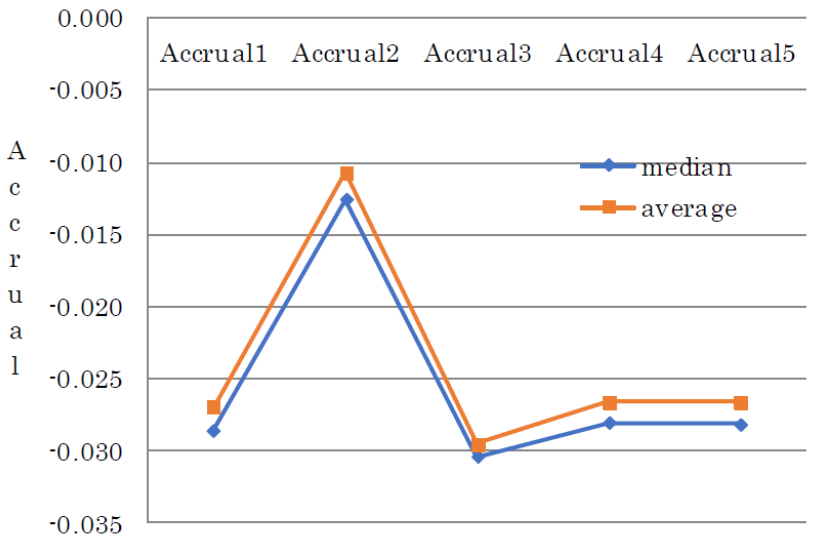

Fig. 3 Median and average of each accrual

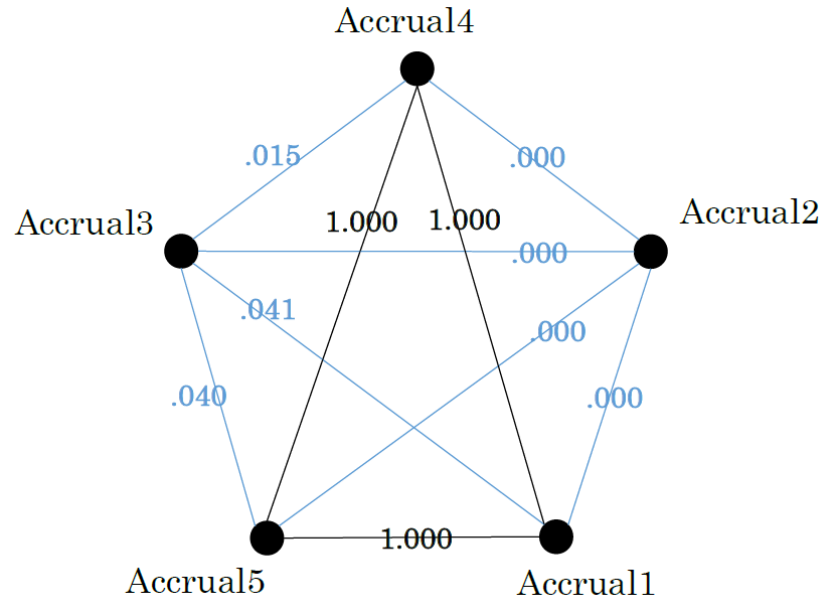

Fig. 4 Multiple comparisons via Dunn detection and adjusted significance probability using the Bonferroni method

\subsection{Examining abnormal accruals}

The average and median values of the calculated abnormal accruals range from -0.008 to 0.000 . In addition, approximately $60 \%$ of all abnormal accruals are within -0.020 and 0.020 , approximately $70 \%$ between -0.30 and 0.030 , approximately $80 \%$ between -0.040 and 0.040 , and approximately $90 \%$ between 0.060 and 0.060 . These ranges shall be referred to as the $60 \%$ range, $70 \%$ range, $80 \%$ range, and $90 \%$ range. Table 4 shows the number of businesses summed up where abnormal accruals are "in the $x \%$ range in the linear model but among the number of businesses outside of the $x \%$ range in the mixed linear model" and "outside of the $x \%$ range in the linear model but among the number of businesses within the $x \%$ range in the mixed linear model." The left side of table 4 is the number of businesses, and the right side is the proportion relative to the total number of businesses. Additionally, table 5 shows the number of businesses where the sign of the abnormal accruals flipped between the linear and mixed linear models.

It is likely that detection of earnings management behavior Accrual 1, Accrual 4, and Accrual 5. 
Table 4 Proportion of overall number of businesses and those that moved $x \%$ out of range due to model change

\begin{tabular}{|c|c|c|c|c|c|c|c|c|c|c|c|}
\hline \multirow{2}{*}{ Model } & \multirow{2}{*}{$\begin{array}{l}x \% \\
\text { Range }\end{array}$} & \multicolumn{5}{|c|}{ Number of Businesses (Companies) } & \multicolumn{5}{|c|}{ Proportion } \\
\hline & & Accrual 1 & Accrual 2 & Accrual 3 & Accrual 4 & Accrual 5 & Accrual 1 & Accrual 2 & Accrual 3 & Accrual 4 & Accrual 5 \\
\hline \multirow{4}{*}{$\begin{array}{l}\text { Jones } \\
\text { Model }\end{array}$} & $60 \%$ & 40 & 28 & 38 & 36 & 34 & 0.075 & 0.053 & 0.071 & 0.068 & 0.064 \\
\hline & $70 \%$ & 25 & 23 & 31 & 35 & 25 & 0.047 & 0.043 & 0.058 & 0.066 & 0.047 \\
\hline & $80 \%$ & 16 & 22 & 13 & 26 & 10 & 0.030 & 0.041 & 0.024 & 0.049 & 0.019 \\
\hline & $90 \%$ & 15 & 10 & 9 & 11 & 7 & 0.028 & 0.019 & 0.017 & 0.021 & 0.013 \\
\hline \multirow{4}{*}{$\begin{array}{l}\text { Modified } \\
\text { Jones } \\
\text { Model }\end{array}$} & $60 \%$ & 41 & 28 & 36 & 38 & 37 & 0.077 & 0.053 & 0.068 & 0.071 & 0.069 \\
\hline & $70 \%$ & 20 & 16 & 22 & 34 & 21 & 0.038 & 0.030 & 0.041 & 0.064 & 0.039 \\
\hline & $80 \%$ & 16 & 21 & 17 & 25 & 14 & 0.030 & 0.039 & 0.032 & 0.047 & 0.026 \\
\hline & $90 \%$ & 14 & 12 & 9 & 11 & 9 & 0.026 & 0.023 & 0.017 & 0.021 & 0.017 \\
\hline \multirow{4}{*}{$\begin{array}{l}\text { Forward } \\
\text { Look- } \\
\text { ing } \\
\text { Model }\end{array}$} & $60 \%$ & 36 & 51 & 42 & 40 & 31 & 0.068 & 0.096 & 0.079 & 0.075 & 0.058 \\
\hline & $70 \%$ & 24 & 38 & 45 & 29 & 23 & 0.045 & 0.071 & 0.084 & 0.054 & 0.043 \\
\hline & $80 \%$ & 36 & 31 & 31 & 21 & 19 & 0.068 & 0.058 & 0.058 & 0.039 & 0.036 \\
\hline & $90 \%$ & 18 & 14 & 12 & 15 & 6 & 0.034 & 0.026 & 0.023 & 0.028 & 0.011 \\
\hline
\end{tabular}

Table 5 Number of companies with flipped signs due to model change

\begin{tabular}{|c|c|c|c|c|c|c|c|c|c|c|}
\hline \multirow{2}{*}{ Model } & \multicolumn{5}{|c|}{ Number of Businesses (Companies) } & \multicolumn{5}{|c|}{ Proportion } \\
\hline & Accrual 1 & Accrual 2 & Accrual 3 & Accrual 4 & Accrual 5 & Accrual 1 & Accrual 2 & Accrual 3 & Accrual 4 & Accrual 5 \\
\hline Jones Model & 23 & 26 & 26 & 20 & 31 & 0.043 & 0.049 & 0.049 & 0.038 & 0.058 \\
\hline $\begin{array}{l}\text { Modified } \\
\text { Jones Model }\end{array}$ & 19 & 23 & 21 & 23 & 29 & 0.036 & 0.043 & 0.039 & 0.043 & 0.054 \\
\hline $\begin{array}{l}\text { Forward } \\
\text { Looking } \\
\text { Model }\end{array}$ & 27 & 44 & 37 & 24 & 23 & 0.051 & 0.083 & 0.069 & 0.045 & 0.043 \\
\hline
\end{tabular}

is improved by using the linear mixed model. Consider Nihon Flush (other manufacturing), which had a reversed sign, and by changing models in Accrual 5 under the Jones Model, it moves from outside the $60 \%$ range into the $60 \%$ range. The coefficient for increase in sales is correct under the linear model, and has a larger value than other industries. Additionally, the change in Nihon Flush's sales is trending downward over time, and the change in sales under the prediction sample also falls greatly into the negative. However, Nihon Flush's abnormal accruals are -0.060 (linear model) and 0.006 (linear mixed model). In other words, the linear mixed model is containing the significant decrease in accruals (a misidentification of earnings management) within a company trend (local effect) of increasing sales.

As such, it is believable that the use of a normal accrual prediction model that considers company differences using a linear mixed model has a certain effect on the detection of earnings management. Moreover, within the Forward-Looking model and Accrual 2 for Pietro (food industry), despite the prediction period's value for depreciable property and equipment being greatly increased over the sample period's, the abnormal accrual is -0.032 (linear model). The linear mixed model, however, is 0.188 , and can detect that this is a company "with large internal changes that are hidden when looking at them from the industry average." Thus, the increase in depreciable property and equipment is the influence of facilities investment, not a detection of earnings management.

Additionally, both the linear and linear mixed models consider businesses observed to have distinctively abnormal accruals. For Wacom (electrical equipment), the abnormal accruals under Accrual 2 and Accrual 3 in all models have large negative values, and the other Accruals have values close to 0. Looking at their financial statements, they appropriated a special loss that included a large impairment loss in the prediction period of March 2017. It cannot be denied that impairment losses, a component of accruals, could be a target of discretionary behavior. However, it is likely that impairment losses are not fully considered by the current normal accrual estimation models.

\section{Conclusion}

The earnings management research that began in the 1970s has since expanded and developed into earnings management detection methods, earnings management motivations / goals, and the economic consequences of earnings management. However, in recent years, the normal accrual prediction model, the foundation for each of these areas of research, has become subject to a great deal of criticism. This paper has divided into three categories and discussed the issues with the normal accrual prediction model and areas surrounding the same, as well as the resulting over-(under-) detection and misidentification.

This paper undertook the following countermeasures for the issues with the normal accrual prediction model. First, it selected and discussed five representative accrual calculation methods. Then, earnings management was redefined as changes to accounting policies / estimates, excessive production, and (partial) manipulation of credit transactions, rather than as a representative variable for accounting discretionary behavior. The paper then adopted a linear mixed model using panel data due to the constancy issue for its estimation method and predicted normal accruals using a regression model for comparison. The interpretation of abnormal accruals was then made to be "whether or not increasing-type (decreasingtype) earnings management was occurring during the prediction period in greater amounts than average earnings managements from the coefficient estimation period."

The results can be summarized as the following:

(1) accrual calculations as a method for reducing pre-tax net income on operating CF are inaccurate, and that it is possible to extract characteristic businesses by using all of the 
other calculation methods.

(2) even if the consideration of business differences is small within the linear mixed model, they make the contribution of being able to detect "companies with large internal changes that are hidden when looking at them from the industry average."

(3) if one is cautious about interpretations of event studies under tax cost theory and the like, it is possible to use abnormal accruals, but it is clear they must not be included in the explanatory variables of an analysis or must not be brought up in the same analysis with proxy variables for substantive discretionary behavior.

As for future research, it may be possible to resolve the issue of under-formulation when calculating abnormal accruals for each model and accrual, then extracting characteristic companies.

\section{References}

[1] Ball, R. (2013). "Accounting Informs Investors and Earnings Management is Rife : Two Questionable Beliefs," The accounting Horizon, 2 (4): 113-129.

[2] Dechow, P.,R. Kothari, and R. L. (1998). "The relation between earnings and cash flows," Journal of Accounting and Economics, 25 (2): 133-168.

[3] Dechow, P.,R. Sloan, and A. Sweeney. (1995). "Detecting Earnings Management," The Accounting Review, 70 (2): 193225 .

[4] Dechow, P., S. Richardson, and I. Tuna. (2003). "Why Are Earnings Kinky? An Examination of the Earnings Management Explanation," Review of Accounting Studies, 8 (2-3): 355-384.

[5] Healy, P. (1985). "The effect of bonus schemes on accounting decision," Journal of Accounting and Economics, 7 (1-3): 85107.

[6] Jones, J. (1991). "Earnings management during import relief investigations," Journal of Accounting Research, 29 (2): 193228.

[7] Natsume S. (2017). "Earnings management through Substantive Discretionary Action for Undertaking M\&A," Tokyo University of Science, Feng Laboratory, Graduation Thesis.

[8] Roychowdhury, S. (2006). "Earnings management thorough real activities manipulation," Journal of Accounting and Economics, 42 (3): 335-370.

[9] Shuto A. (2010). "Earnings management in Japanese Corporations -Theory and Evidence," Chuoukeizaisha.

[10] Subramanyam, K. R. (1996). "The pricing of discretionary accruals," Journal of Accounting and Economics, 22: 249-281.

[11] Suda K. (2000). "Functions of Financial Accounting," Hakuto.

[12] Xie, H. (2001). "The mispricing of abnormal accruals," The Accounting Review, 76 (July): 357-373.

[13] Yaekura T. (2012). "Fundamentals of Profit Manipulation Research," in "Fundamentals of Accounting Standards Research," Chuoukeizaisha.

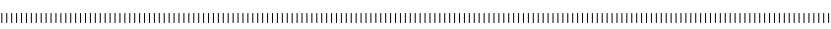

\section{Ryota TAKahashi}

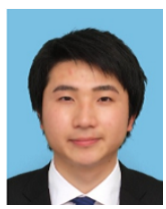

is a master course student in graduate school of Science and Technology, Tokyo University of Science. He focuses on the Normal Accrual Prediction Model, in order to detect earnings management. He is going to contribute to detect earnings management via Jones Model.

\section{Ling FeNG}

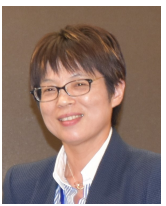

is an professor of Faculty of Science and Technology, Tokyo University of Science. She is an engineering master and a Ph.D. of Economics. She is also a member of Japanese Association for Management Accounting (JAMA). 